\title{
Mourning the loss of Prof. Franco Cerrina
}

On July 12, Karolyn Labes, managing editor of $\mathrm{JM}^{3}$, gave me the sad news of Franco Cerrina's passing. Franco and I had just communicated. He wrote me on a $\mathrm{JM}^{3}$ matter on June 13, and, after studying the case, I replied on July 7. He may not have had a chance to read the reply!

Franco became an SPIE fellow in 2008. He was a professor at the University of Wisconsin from 1990 to 2008 and was, at the time of his death, a professor at Boston University. Professor Cerrina held many director and chair professor positions and founded NimbleGen Systems in 1999. In addition to being a fellow of SPIE, he was also a fellow of APS, OSA, and IEEE. Franco was a founding associate editor of $\mathrm{JM}^{3}$. Recently he served as the guest editor of the EUV Interference Lithography special section.

I have known Franco since the 1980s because of his work championing $\mathrm{x}$-ray proximity printing. Although I was a strong and vocal critic of the technology, we both remained objective scientists. We could each hold on to our commitment to differing technologies and remained good friends. He invited me to visit his lab and the beam line at the University of Wisconsin. I got to know some of his best students and had the opportunity to persuade them to join IBM.

Following are reactions from the many members of the board of editors of $\mathrm{JM}^{3}$, when I informed them of Franco's unfortunate passing away.

Bill Arnold: "This is a great shock! Franco was a strong scholar, a terrific teacher and colleague to us, and we will miss him very much. I certainly enjoyed my times with him."

Chris Progler: "I remember working with Franco as far back as IBM X Ray program in Brookhaven Labs. He always stood out as a great scientist/educator and also a great human being."
Ed Motamedi: "I am so sad to read this news about Franco; encouraging in a time of loss and grief is what we all wish would come easily. Unfortunate it is not that easy. Many come in this world and leave with no signature of existence and humanity. I did not have opportunity to know closely Franco but learning from his biography and understanding of the situation that he left this world in his lab it really touched my heart. He has done so much for our societies and our culture that one is amazed. My deepest sympathies to his family and his loved ones."

Rejeshuni Ramesham: "My deepest condolences to his loved ones. He will be really missed."

Anthony Yen: "Close to the completion of my $\mathrm{PhD}$ in Spring of 1991, Hank suggested to me one day to take a post-doc position at $U$. of Wisconsin to further my training in x-ray lithography under Franco. I thought about it for a while but decided to keep the promise I had made to $\mathrm{TI}$ since I had by then accepted their offer. Otherwise, I could have worked for Franco as a post-doc."

More details on this event can be found at http:// www.bu.edu/today/node/11245.

Franco, we miss you!

\section{Burn J. Lin}

\section{Editor-in-Chief}

